Research Article

\title{
Assessment of Flexural Behavior of Pultruded GFRP Laminates for Bridge Deck Applications
}

\author{
Youyou Zhang, ${ }^{1}$ Ayman Mosallam, ${ }^{2}$ Yuqing Liu $\left(\mathbb{D},{ }^{3}\right.$ Yun Sun, ${ }^{3}$ Haohui Xin $\mathbb{D}^{4},{ }^{4}$ \\ and Jun $\mathrm{He} \mathbb{i D}^{5}$ \\ ${ }^{1}$ Department of Civil and Environmental Engineering, University of California, Davis, CA, USA \\ ${ }^{2}$ Department of Civil and Environment Engineering, University of California, Irvine, CA, USA \\ ${ }^{3}$ Department of Bridge Engineering, Tongji University, Shanghai, China \\ ${ }^{4}$ Faculty of Civil Engineering and Geosciences, Delft University of Technology, Delft, Netherlands \\ ${ }^{5}$ School of Civil Engineering, Changsha University of Science \& Technology, Hunan, China \\ Correspondence should be addressed to Haohui Xin; h.xin@tudelft.nl
}

Received 27 December 2018; Accepted 4 April 2019; Published 2 May 2019

Academic Editor: Aniello Riccio

Copyright ( 2019 Youyou Zhang et al. This is an open access article distributed under the Creative Commons Attribution License, which permits unrestricted use, distribution, and reproduction in any medium, provided the original work is properly cited.

\begin{abstract}
In this study, flexural behaviors of the pultruded composite laminate were evaluated through experiments and theoretical analysis. Three-point flexural tests were performed for pultruded specimens. The typical failure mode for the longitudinal flexural specimens was local crush on the top surface accompanied with local cracks on the bottom surface at midspan. For the transverse tests, the specimens presented a failure pattern with local cracks initiated and propagated at both the top and bottom sides at the midspan. Theoretical analysis, based on micromechanics and macromechanics, was performed to predict flexural deformation and stress distribution of the pultruded laminate beam. Based on the continuum damage model proposed by the authors, this paper mainly investigates the flexural behavior and failure pattern of pultruded lamination. The theoretical and finite element results agreed well with the test results. The results can provide a reference for the design of the structural pultruded modular systems.
\end{abstract}

\section{Introduction}

With high strength, lightweight, good durability behavior and continuous producing features, pultruded fiber reinforced polymer (PFRP) composites are becoming the preferred materials in both the new structures and in the repair and rehabilitation of the existing structures $[1,2]$. Pultruded glass fiber reinforced polymer (GFRP) composites have been applied in pedestrian bridges as well as in the bridge deck replacement primarily due to their economic benefits [3-16].

Careful attention should be paid to the mechanical properties of the GFRP laminates when designing the GFRP structures since GFRP laminates are orthotropic, and the shear modulus is independent of the elastic modulus and Poisson's ratio. Besides, pultruded GFRP laminates with different stacking-sequence show different mechanical behaviors. Thus, the GFRP laminates should be designed with multiscale strategy in the practice $[17,18]$. Considering no specification provides mechanical properties for the GFRP laminates, we conducted this study aiming to obtain a deeper understanding of the flexural behavior of the GFRP laminates.

In this study, the longitudinal and transverse flexural strength and moduli are evaluated through experiments. Theoretical analysis are performed for predicting deformation and stress distribution of the pultruded laminate specimens based on both micromechanics and macromechanics. Theoretical analysis was performed to predict flexural deformation and stress distribution of the pultruded laminate beam. Based on the continuum damage model 
proposed by the authors, this paper investigates the flexural behavior and failure pattern of pultruded lamination. The study in this paper can be a reference for the design of structural pultruded modular systems.

\section{Experimental Programs}

2.1. Materials and Specimens. The properties of fibers and resin are listed in Tables 1 and 2 based on $[4,19,20]$. Figure 1 presents the laminate layup of specimens [19]. Two different types of specimens are tested in the study. The specimens cut parallel to the roving direction are denoted as Longitudinal specimens, while the specimens cut perpendicular to the roving direction are denoted as Transverse specimens. The dimensions of all specimens are $200.0 \mathrm{~mm} \times 15.0 \mathrm{~mm} \times$ $10.0 \mathrm{~mm}$ (length $\times$ width $\times$ thickness).

2.2. Test Procedures. As shown in Figure 2, three-point bending tests were used to investigate both the longitudinal and transverse flexural behaviors of pultruded GFRP laminates. Five identical specimens were fabricated for each loading type with a clear span of $160.0 \mathrm{~mm}$ and a length-to-thickness ratio of $16: 1$. The detailed procedures could be referred to the GB/T 1449-2005 standard procedures [21], and the ultimate flexural capacity, $\sigma_{\mathrm{f}}$, and the flexural stiffness, $E_{\mathrm{f}}$, were obtained using equations (1) and (2):

$$
\begin{aligned}
& \sigma_{\mathrm{f}}=\frac{3 P l}{2 b h^{2}}, \\
& E_{\mathrm{f}}=\frac{l^{3}}{4 b h^{3}} \frac{\Delta P}{\Delta S} .
\end{aligned}
$$

\subsection{Experimental Results}

2.3.1. Flexural Strength and Modulus. The flexural strength when the initial failure of the first lamina occur is denoted as "First ply failure strength." The flexural test results of the pultruded lamination are listed in Table 3 with the first ply failure strength denoted as FS, the flexural strength denoted as $S$, and the flexural modulus denoted as $E$. The subscript "av" denotes the average value, the subscript "95" denotes the value with $95 \%$ guaranteed rate, and SD denotes the standard deviation. As shown in Table 3, the value of the transverse $\mathrm{FS}_{\mathrm{av}}$ is $65.22 \mathrm{MPa}$, while the transverse value $\mathrm{FS}_{95}$ is $60.31 \mathrm{MPa}$. The longitudinal average strength $S_{\mathrm{av}}$ is $759.49 \mathrm{MPa}$ and the longitudinal $S_{95}$ is $728.73 \mathrm{MPa}$. The transverse $S_{\mathrm{av}}$ is $175.96 \mathrm{MPa}$, and the transverse value of $S_{95}$ is $155.57 \mathrm{MPa}$. The longitudinal average modulus value of $E_{\mathrm{av}}$ is $33.36 \mathrm{GPa}$, while the longitudinal $E_{95}$ modulus value is $31.25 \mathrm{GPa}$. Also, the transverse $E_{\text {av }}$ and $E_{95}$ moduli values are $14.35 \mathrm{GPa}$ and $13.40 \mathrm{GPa}$, respectively. It is noted that no first ply failure occurs for longitudinal loading.
2.3.2. Load-Displacement Relationship. The typical loaddisplacement curves are shown in Figure 3. The load resisted by the longitudinal specimen increased linearly prior to the sharp decrease that occurred at the ultimate load. The load of the transverse specimen increased linearly from $0.0 \mathrm{~N}$ to $456.2 \mathrm{~N}$ and later was increased nonlinearly with reduced curve slope until failure. The nonlinearity is because the failure of the transverse specimen lamina occurred progressively ply by ply that resulted in a gradual degradation of effective stiffness of the specimen.

2.3.3. Failure Modes. The failure pattern of flexural specimens is illustrated in Figure 4. Failure mode of the longitudinal flexural specimen was local crush on the top surface accompanied with the propagation of local cracks on the bottom surface at the midspan of the specimen. For the transverse flexural specimen, the failure was because of the occurrence of local cracks that propagated on the bottom surface at the midspan.

\section{Theoretical Analysis}

3.1. Mechanical Properties of Lamina. The predicted thickness of the lamina and associated fiber volume fraction, the engineering constants of lamina, and the ultimate strengths of the lamina are reported in the authors' previous work $[14-16,19]$. In this analysis, the fabric layers strength was assumed as the strength for unidirectional roving layer with special angles. Future research on the ultimate strength of fabric layer is expected.

\subsection{Laminate Flexural Analysis}

3.2.1. Classical Laminate Theory (CLT). For a small sectional rotation, the displacement along the $X$ direction, $u$, the displacement along $Y$ direction, $v$, and the displacement along the $Z$ direction, $w$, are expressed as follows [22, 23]:

$$
\begin{gathered}
u=u_{0}-z \frac{\partial w}{\partial x} \\
v=v_{0}-z \frac{\partial w}{\partial y} \\
w=w(x, y),
\end{gathered}
$$

where $u_{0}$ and $v_{0}$ are the displacements at the neutral plane. The laminate strains are given by the following equations:

$$
\left\{\begin{array}{l}
\varepsilon_{x}=\frac{\partial u}{\partial x}=\frac{\partial u_{0}}{\partial x}-z \frac{\partial^{2} w}{\partial x^{2}} \\
\varepsilon_{y}=\frac{\partial v}{\partial y}=\frac{\partial v_{0}}{\partial y}-z \frac{\partial^{2} w}{\partial y^{2}} \\
\gamma_{x y}=\frac{\partial u}{\partial y}+\frac{\partial v}{\partial x}=\frac{\partial u_{0}}{\partial y}+\frac{\partial v_{0}}{\partial x}-2 z \frac{\partial^{2} w}{\partial x \partial y}
\end{array}\right.
$$


TABLe 1: Mechanical properties of E-glass fibers [19].

\begin{tabular}{lcccccc}
\hline $\begin{array}{l}\text { Longitudinal } \\
\text { modulus }\left(E_{\mathrm{f} 1}\right)\end{array}$ & $\begin{array}{c}\text { Transverse } \\
\text { modulus }\left(E_{\mathrm{f} 2}\right)\end{array}$ & $\begin{array}{c}\text { Poisson's } \\
\text { ratio }\left(v_{\mathrm{f}}\right)\end{array}$ & $\begin{array}{c}\text { Shear modulus } \\
\left(G_{\mathrm{f}}\right)\end{array}$ & $\begin{array}{c}\text { Tensile strength } \\
\left(X_{\mathrm{ft}}\right)\end{array}$ & $\begin{array}{c}\text { Compressive strength } \\
\left(X_{\mathrm{fc}}\right)\end{array}$ & \begin{tabular}{c} 
Density $(\rho)$ \\
\hline $74.0 \mathrm{GPa}$
\end{tabular} \\
$74.0 \mathrm{GPa}$ & 0.20 & $30.80 \mathrm{GPa}$ & $2,150 \mathrm{MPa}$ & $1,450 \mathrm{MPa}$ & $2,560 \mathrm{~kg} / \mathrm{m}^{3}$ \\
\hline
\end{tabular}

TABle 2: Mechanical properties of epoxy resin [19].

\begin{tabular}{lcccccc}
\hline $\begin{array}{l}\text { Modulus } \\
\left(E_{\mathrm{m}}\right)\end{array}$ & $\begin{array}{c}\text { Poisson's } \\
\text { ratio }\left(v_{\mathrm{m}}\right)\end{array}$ & $\begin{array}{c}\text { Shear modulus } \\
\left(G_{\mathrm{m}}\right)\end{array}$ & $\begin{array}{c}\text { Tensile strength } \\
\left(X_{\mathrm{mt}}\right)\end{array}$ & $\begin{array}{c}\text { Compressive strength } \\
\left(X_{\mathrm{mc}}\right)\end{array}$ & $\begin{array}{c}\text { Shear strength } \\
\left(S_{\mathrm{m}}\right)\end{array}$ & $\begin{array}{c}\text { Density } \\
(\rho)\end{array}$ \\
\hline $3.35 \mathrm{GPa}$ & 0.35 & $1.24 \mathrm{GPa}$ & $80 \mathrm{MPa}$ & $120 \mathrm{MPa}$ & $75 \mathrm{MPa}$ & $1,160 \mathrm{~kg} / \mathrm{m}^{3}$ \\
\hline
\end{tabular}

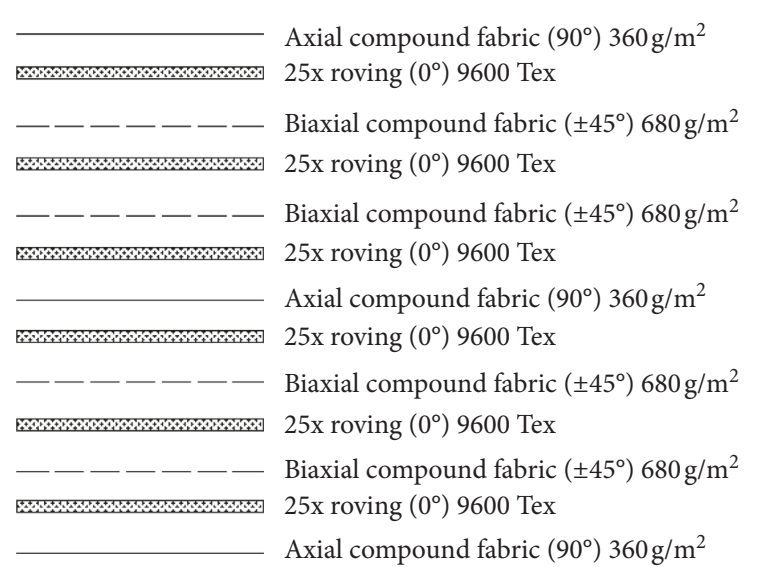

Figure 1: Laminate layup.

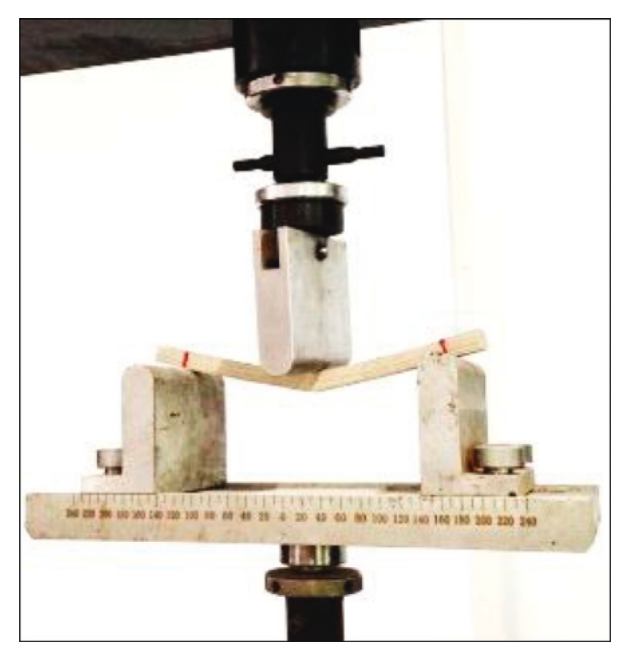

FIgURE 2: Flexural test setup.

Thus

$$
\{\varepsilon\}=\left\{\varepsilon^{0}\right\}+z\{k\}=\left\{\begin{array}{c}
\varepsilon_{x}^{0} \\
\varepsilon_{y}^{0} \\
\gamma_{x y}^{0}
\end{array}\right\}+z\left\{\begin{array}{c}
k_{x} \\
k_{y} \\
k_{x y}
\end{array}\right\}
$$

TABLe 3: Summary of test results.

\begin{tabular}{lcc}
\hline Item & Longitudinal & Transverse \\
\hline First ply failure strength & & \\
FS $_{\text {av }}(\mathrm{MPa})$ & - & 65.22 \\
$\mathrm{FS}_{95}(\mathrm{MPa})$ & - & 60.31 \\
$\mathrm{SD}$ & - & 3.96 \\
\hline Flexural strength & & \\
$S_{\mathrm{av}}(\mathrm{MPa})$ & 759.49 & 175.96 \\
$S_{95}(\mathrm{MPa})$ & 728.73 & 155.57 \\
SD & 24.77 & 16.41 \\
\hline Flexural modulus & & \\
$E_{\mathrm{av}}(\mathrm{MPa})$ & 33.36 & 14.35 \\
$E_{95}(\mathrm{MPa})$ & 31.25 & 13.40 \\
SD & 1.70 & 0.77 \\
\hline
\end{tabular}

where

$$
\begin{aligned}
\varepsilon_{x}^{0} & =\frac{\partial u_{0}}{\partial x}, \\
\varepsilon_{y}^{0} & =\frac{\partial v_{0}}{\partial y}, \\
\gamma_{x y}^{0} & =\frac{\partial u_{0}}{\partial y}+\frac{\partial v_{0}}{\partial x}, \\
k_{x} & =-\frac{\partial^{2} w}{\partial x^{2}} \\
k_{y} & =-\frac{\partial^{2} w}{\partial y^{2}}, \\
k_{x y} & =-2 \frac{\partial^{2} w}{\partial x \partial y} .
\end{aligned}
$$

Based on Hooke's law, the stress-strain relationship of each lamina is given as

$$
\{\sigma\}^{(k)}=[\bar{Q}]_{k}\{\varepsilon\}^{(k)}=[\bar{Q}]_{k}\left\{\varepsilon_{0}\right\}+[\bar{Q}]_{k}\{\kappa\} z,
$$

where the effective stiffness matrix $\bar{Q}$ is calculated by the following equations: 


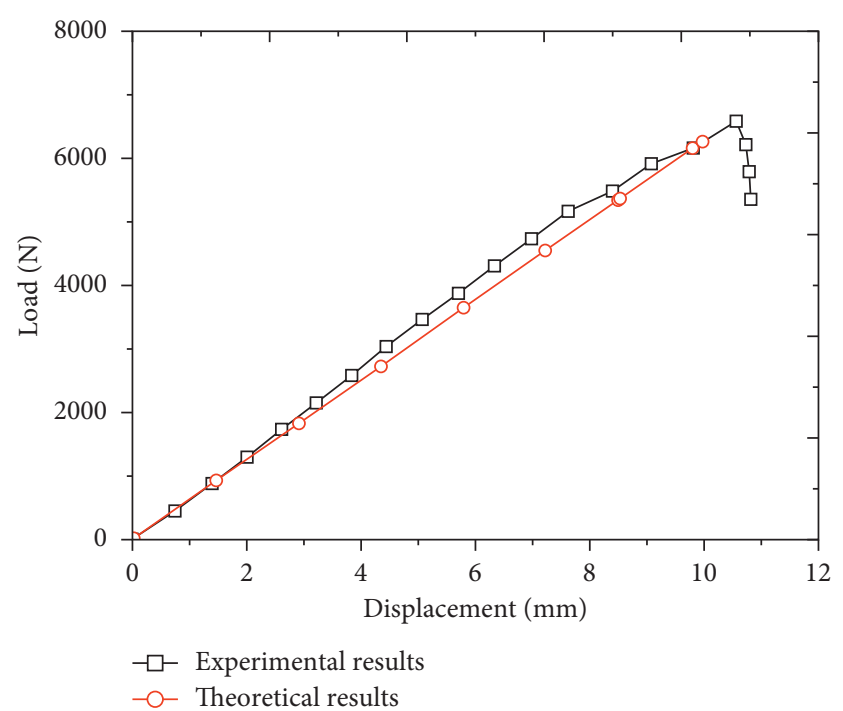

(a)

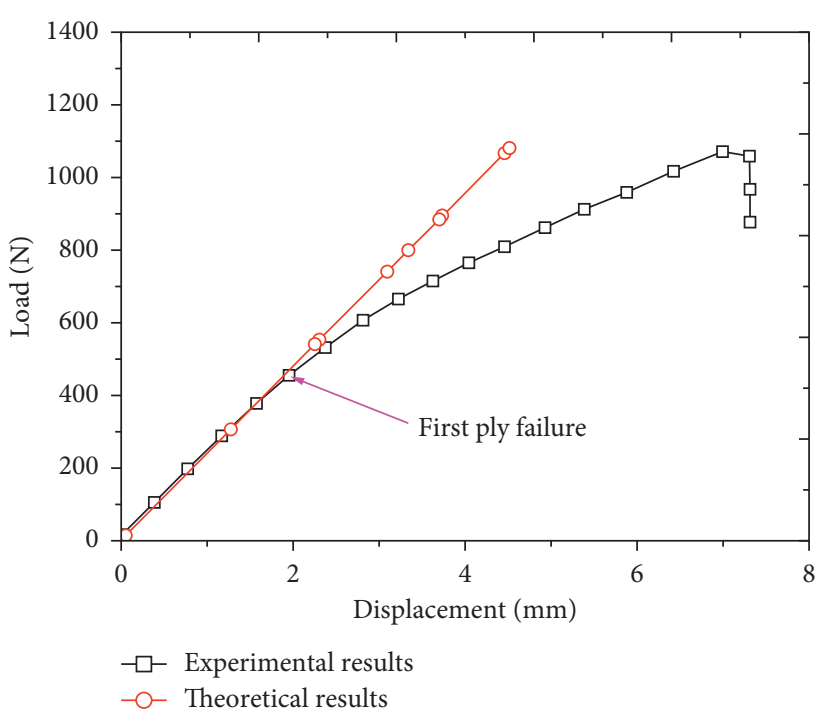

(b)

FIgURE 3: Load-displacement curve. (a) Longitudinal. (b) Transverse.

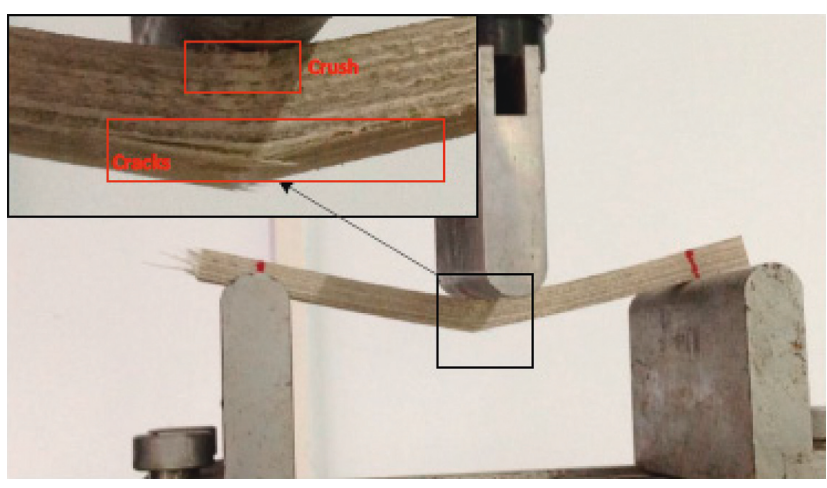

(a)

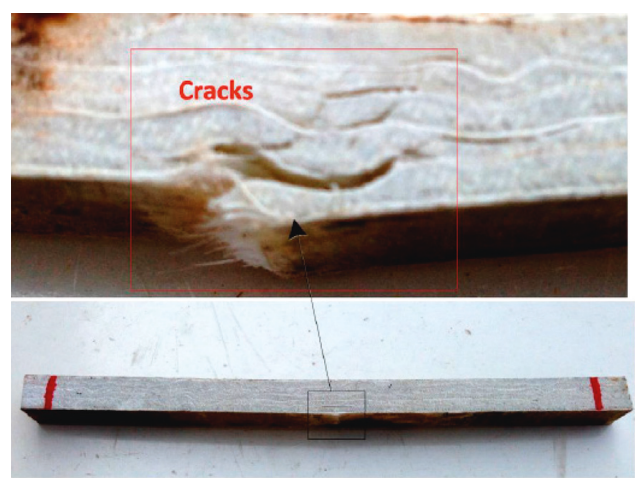

(b)

FIgURE 4: Failure modes. (a) Longitudinal. (b) Transverse.

$$
\begin{aligned}
& {[\bar{Q}]=[T]^{-1}[Q][T]^{-T},} \\
& {[T]=\left[\begin{array}{ccc}
\cos ^{2} \theta & \sin ^{2} \theta & 2 \cos \theta \sin \theta \\
\sin ^{2} \theta & \cos ^{2} \theta & -2 \cos \theta \sin \theta \\
-\cos \theta \sin \theta & \cos \theta \sin \theta & \cos ^{2} \theta-\sin ^{2} \theta
\end{array}\right],} \\
& {[Q]=\left[\begin{array}{crr}
\frac{E_{1}}{1-v_{12} v_{21}} & \frac{v_{12} E_{2}}{1-v_{12} v_{21}} & 0 \\
\frac{v_{12} E_{2}}{1-v_{12} v_{21}} & \frac{E_{2}}{1-v_{12} v_{21}} & 0 \\
0 & 0 & G_{12}
\end{array}\right] .}
\end{aligned}
$$

By introducing the axial force and moment of a unit length, the force-stress and moment-stress relationships are expressed by the following equations based on definition in $[18,20]$ :

$$
\begin{aligned}
\{N\} & =\left\{\begin{array}{c}
N_{x} \\
N_{y} \\
N_{x y}
\end{array}\right\}=\int_{-h / 2}^{h / 2}\left\{\begin{array}{c}
\sigma_{x} \\
\sigma_{y} \\
\tau_{x y}
\end{array}\right\} d z=\sum_{k=1}^{n} \int_{z_{k-1}}^{z_{k}}\left\{\begin{array}{c}
\sigma_{x} \\
\sigma_{y} \\
\tau_{x y}
\end{array}\right\} d z, \\
\{M\} & =\left\{\begin{array}{c}
M_{x} \\
M_{y} \\
M_{x y}
\end{array}\right\}=\int_{-h / 2}^{h / 2}\left\{\begin{array}{c}
\sigma_{x} \\
\sigma_{y} \\
\tau_{x y}
\end{array}\right\} z d z \\
& =\sum_{k=1}^{n} \int_{z_{k-1}}^{z_{k}}\left\{\begin{array}{c}
\sigma_{x} \\
\sigma_{y} \\
\tau_{x y}
\end{array}\right\} z d z,
\end{aligned}
$$

which could be expressed as

$$
\left\{\begin{array}{l}
N \\
M
\end{array}\right\}=\left[\begin{array}{ll}
A & B \\
B & D
\end{array}\right]\left\{\begin{array}{l}
\varepsilon^{0} \\
\kappa
\end{array}\right\},
$$


where $[22,23]$

$$
\left\{\begin{array}{l}
A_{i j}=\int_{-h / 2}^{h / 2} \bar{Q}_{i j} d z=\sum_{k=1}^{n}\left(\bar{Q}_{i j}\right)_{k}\left(z_{k}-z_{k-1}\right), \\
B_{i j}=\int_{-h / 2}^{h / 2} \bar{Q}_{i j} z d z=\frac{1}{2} \sum_{k=1}^{n}\left(\bar{Q}_{i j}\right)_{k}\left(z_{k}^{2}-z_{k-1}^{2}\right), \\
C_{i j}=\int_{-h / 2}^{h / 2} \bar{Q}_{i j} z^{2} d z=\frac{1}{3} \sum_{k=1}^{n}\left(\bar{Q}_{i j}\right)_{k}\left(z_{k}^{3}-z_{k-1}^{3}\right) .
\end{array}\right.
$$

3.2.2. Flexural Analysis. In this analysis, the following assumptions are made: (i) the displacement, $v$, along the $Y$ direction is assumed to be zero and (ii) the displacement, $w$, along the $Z$ direction is assumed to be uniform along the width. Based on these assumptions, the force and moment in terms of displacement are expressed by the following expressions:

$$
\begin{aligned}
& N_{x}=A_{11} \frac{\partial u_{0}}{\partial x}-B_{11} \frac{\partial^{2} w}{\partial x^{2}}, \\
& M_{x}=B_{11} \frac{\partial u_{0}}{\partial x}-D_{11} \frac{\partial^{2} w}{\partial x^{2}} .
\end{aligned}
$$

As shown in Figure 5(a), the moment, shear force, and axial force are expressed as

$$
\begin{aligned}
& M_{x}= \begin{cases}\frac{P x}{2 b}, & 0 \leq x<\frac{l}{2}, \\
\frac{P(l-x)}{2 b}, & \frac{l}{2} \leq x \leq l,\end{cases} \\
& F_{x}= \begin{cases}\frac{P}{2 b}, & 0 \leq x<\frac{l}{2}, \\
-\frac{P}{2 b}, & \frac{l}{2} \leq x \leq l,\end{cases} \\
& N_{x}=0 .
\end{aligned}
$$

Since the axial force is zero, the moment is expressed as

$$
M_{x}=\left(\frac{B_{11}^{2}}{A_{11}}-D_{11}\right) \frac{\partial^{2} w}{\partial x^{2}}
$$

The boundary conditions of the three-point bending loading protocol are

$$
\begin{gathered}
w=0, \quad \text { when } x=0 \text { or } x=l, \\
w^{\prime}=0, \quad \text { when } x=0 \text { or } x=l .
\end{gathered}
$$

Combining equations (14), (16), and (17) yields

$$
w= \begin{cases}\frac{1}{12 C} P x^{3}-\frac{1}{16 C} P l^{2} x, & 0 \leq x<\frac{l}{2}, \\ -\frac{1}{12 C} P x^{3}+\frac{1}{4 C} P l x^{2}-\frac{3}{16 C} P l^{2} x+\frac{1}{48 C} P l^{3}, & \frac{l}{2} \leq x \leq l,\end{cases}
$$

where

$$
\begin{aligned}
& C_{x}=\left(\frac{B_{11}^{2}}{A_{11}}-D_{11}\right), \\
& C_{y}=\left(\frac{B_{22}^{2}}{A_{22}}-D_{22}\right) .
\end{aligned}
$$

The normal stress of each lamina is obtained by using equation (7), which is expressed as

$$
\begin{aligned}
& \sigma_{x}^{(k)}=\frac{1}{C_{x}}\left(\frac{B_{11}}{A_{11}}-z\right) \bar{Q}_{11}^{(k)} M_{x}, \\
& \sigma_{y}^{(k)}=\frac{1}{C_{y}}\left(\frac{B_{22}}{A_{22}}-z\right) \bar{Q}_{22}^{(k)} M_{y} .
\end{aligned}
$$

As shown in Figure 5(b), the equilibrium equation is given as

$$
\int_{z_{i}}^{h / 2} \sigma_{x} d z+\tau_{x z}^{(k)} d_{x}-\int_{z_{i}}^{h / 2}\left(\sigma_{x}+d \sigma_{x}\right) d z=0 .
$$

Also, the shear stress of each lamina is obtained based on equation (22).

$$
\tau_{x z}^{(k)}=\frac{F_{x}}{C}\left[\frac{B_{11}}{A_{11}} \int_{z_{i}}^{h / 2} Q_{11}^{(k)} d_{z}-\int_{z_{i}}^{h / 2} Q_{11}^{(k)} z d_{z}\right] .
$$

Thus

$$
\tau_{x z}^{(k)}=\frac{F_{x}}{C_{x}}\left[\frac{B_{11}}{A_{11}} \sum_{i=1}^{k} Q_{11}^{(k)}\left(z_{k}-z_{k-1}\right)-\frac{1}{2} \sum_{i=1}^{k} Q_{11}^{(k)}\left(z_{k}^{2}-z_{k-1}^{2}\right)\right] \text {. }
$$

Similar to the longitudinal shear stress, the transverse shear stress is expressed as

$$
\tau_{y z}^{(k)}=\frac{F_{y}}{C_{y}}\left[\frac{B_{22}}{A_{22}} \sum_{i=1}^{k} Q_{22}^{(k)}\left(z_{k}-z_{k-1}\right)-\frac{1}{2} \sum_{i=1}^{k} Q_{22}^{(k)}\left(z_{k}^{2}-z_{k-1}^{2}\right)\right] .
$$

3.3. Theoretical Results. Figure 3 shows a comparison between test and theoretical deformations. The loaddisplacement relationship for the longitudinal flexural specimen or transverse flexural specimen obtained from equation (19) agrees well with corresponding experimental value prior to final failure (Figure 3(a)) or prior to the first ply failure (Figure 3(b)). Before the failure load, the 


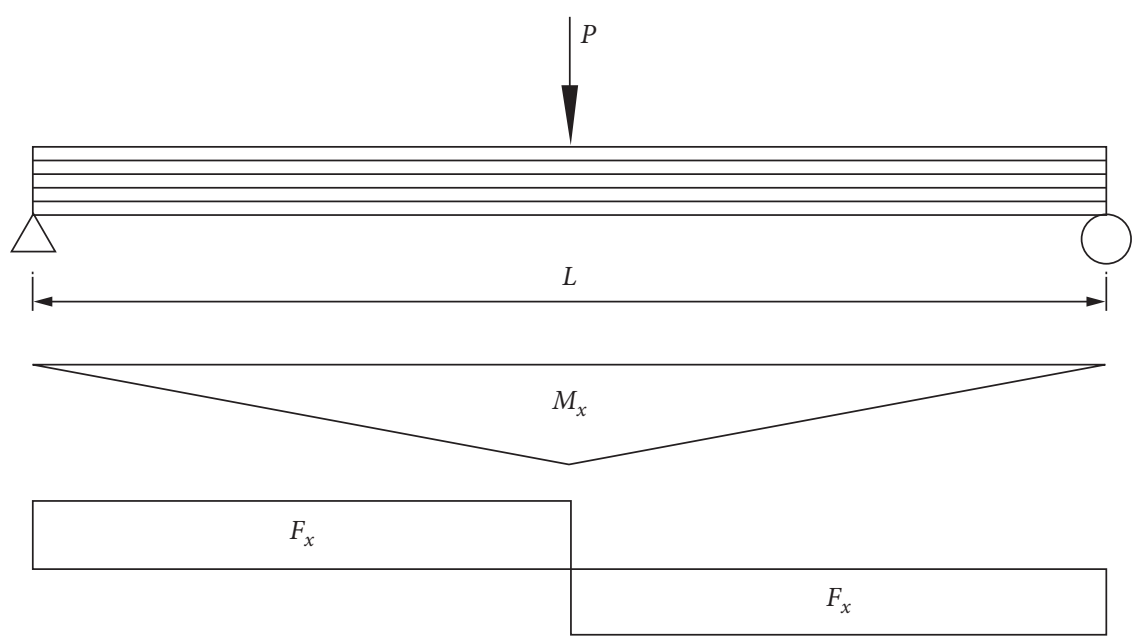

(a)
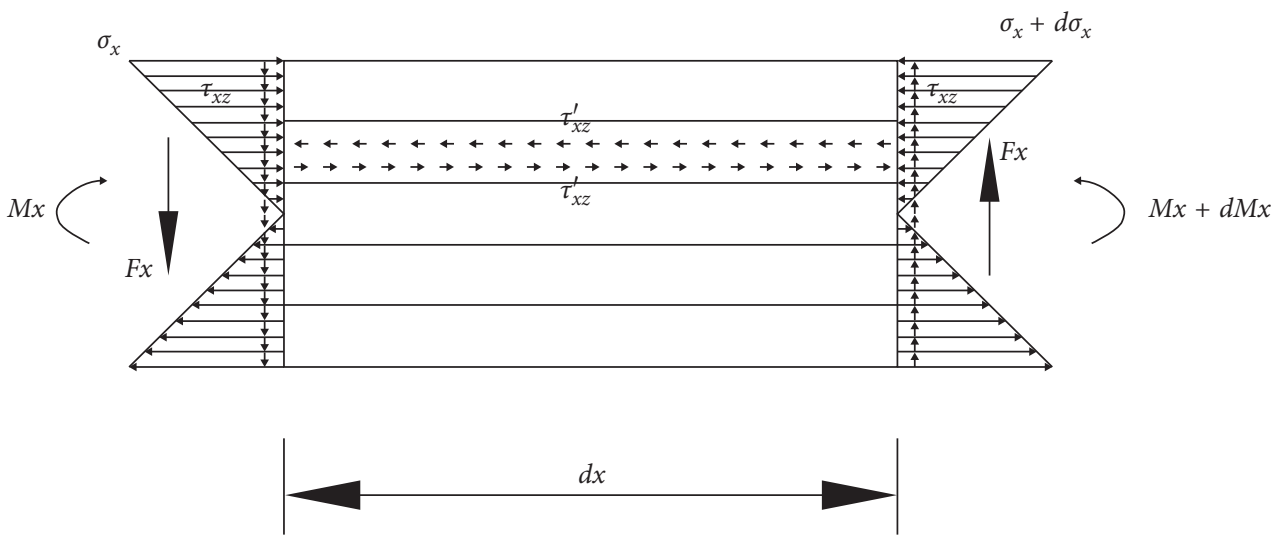

(b)

FIGURE 5: Loads and flexural stress distributions of three-point loading laminated beam. (a) Bending moment and shear force distribution. (b) Stress distribution of infinitesimal section.

experimental deflection is larger than the corresponding theoretical value because of the stiffness degradation.

The stress distribution of each lamina along the thickness is shown in Figure 6. The maximum normal stress of the longitudinal specimen was $1,010.0 \mathrm{MPa}$ that occurred in the $0^{\circ}$-lamina close to the top and bottom surfaces when the load was increased to its maximum value. For the transverse specimen, the maximum normal stress of was $214.0 \mathrm{MPa}$ and occurred in the $90^{\circ}$-lamina close to both the top and bottom surfaces when the first-ply failure occurred. The maximum shear stress for both the longitudinal and transverse specimens in the $0^{\circ}$-lamina occurred near the top and bottom surfaces of the laminate. The maximum shear stress of longitudinal specimen was 17.2 $\mathrm{MPa}$ which occurred when the load reached its maximum value. For the transverse specimen, the maximum shear stress was $3.1 \mathrm{MPa}$ when the first-ply failure occurred.

\section{Numerical Simulation}

4.1. Continuum Damage Model. To better predict the flexural behavior of pultruded GFRP laminations, the continuum damage material model and user-material subroutine,
UMAT, in ABAQUS/Standard [24] proposed in the author's previous publication [19] were employed. The reader can refer to [19] for the details of this damage model, including damaged material response, initial failure criteria, damage assessment, KKT loading/unloading conditions, and viscous regularization. The authors predict the tensile and in-plane shear behavior with proposed damage model in the previous work [19], and the flexural behaviors were evaluated in this paper.

4.2. Numerical Simulation Description and Results. As shown in Figure 7, three-dimensional nonlinear models for the three-point bending specimens were built using the ABAQUS/Standard commercial finite element platform [24]. The lamina was simulated by the solid element C3D8R with enhanced hourglass stiffness control strategy. As shown in Figure 7, the translation " $U Z$ " at the support point of the bottom surface was constrained, and the "UX" and " $U Y$ " translations at the middle span of the bottom surface were constrained. In addition, surface-to-surface contact was employed at the interfaces of the steel loading fixture. The normal property of the contact interaction was set as "hard," 


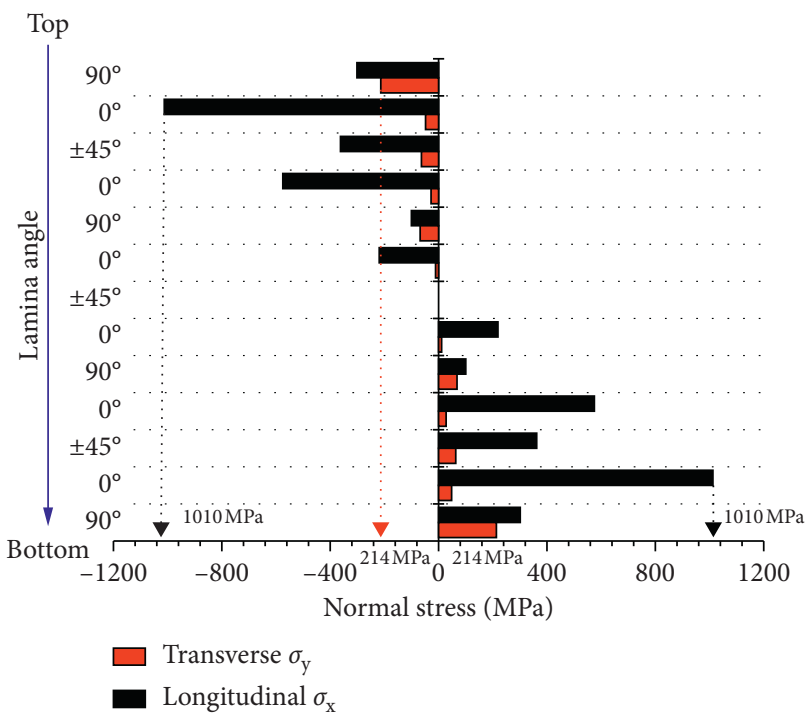

(a)

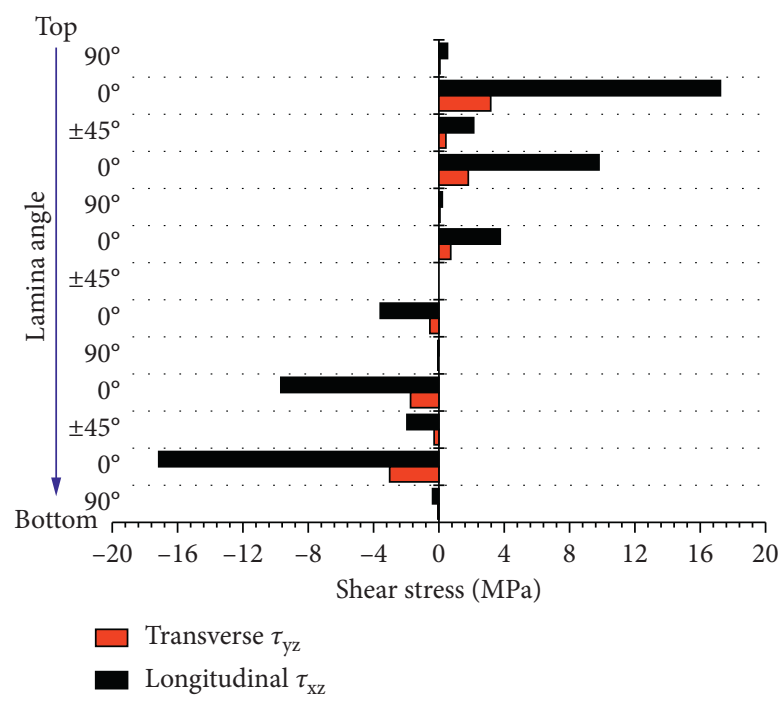

(b)

Figure 6: Laminate stress distribution along thickness direction. (a) Normal stress. (b) Shear stress.

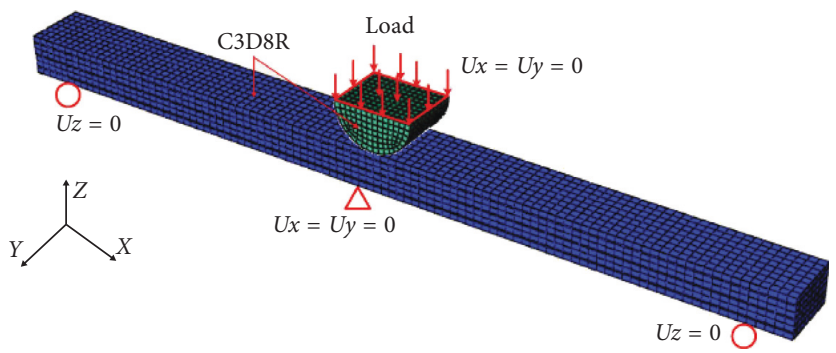

Figure 7: Finite element model for three-point bending.

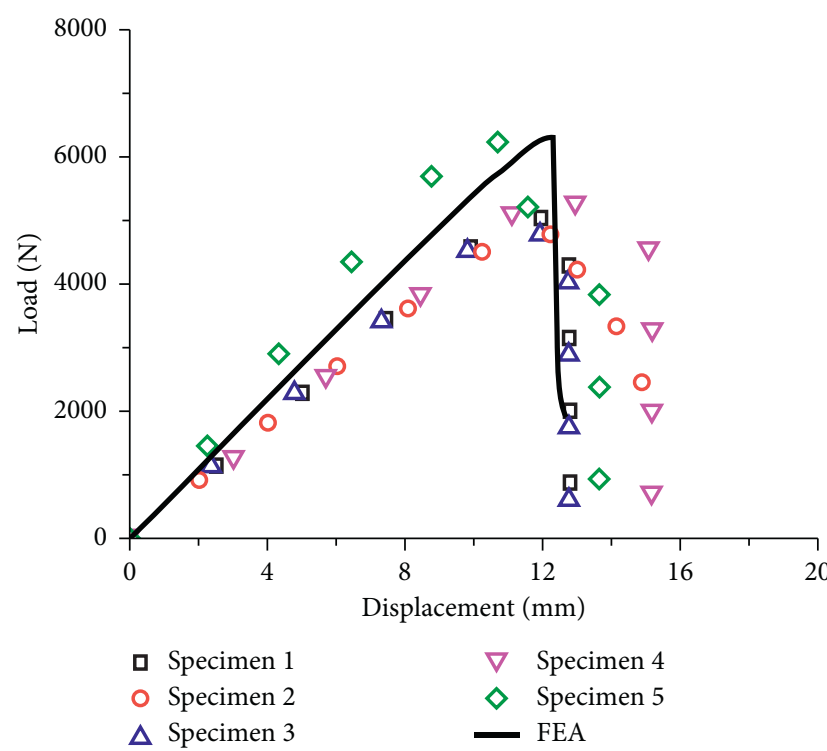

(a)

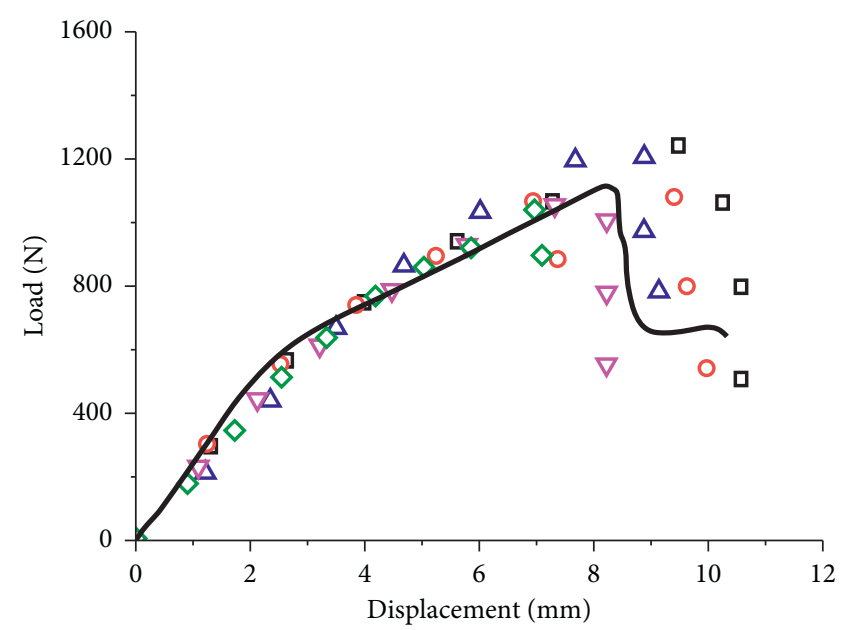
- Specimen 1
- Specimen 2
$\nabla \quad$ Specimen 4
$\Delta$ Specimen 3
$\diamond$ Specimen 5

(b)

FIgURE 8: A comparison between numerical and experimental load-displacement relationship. (a) Longitudinal. (b) Transverse. 


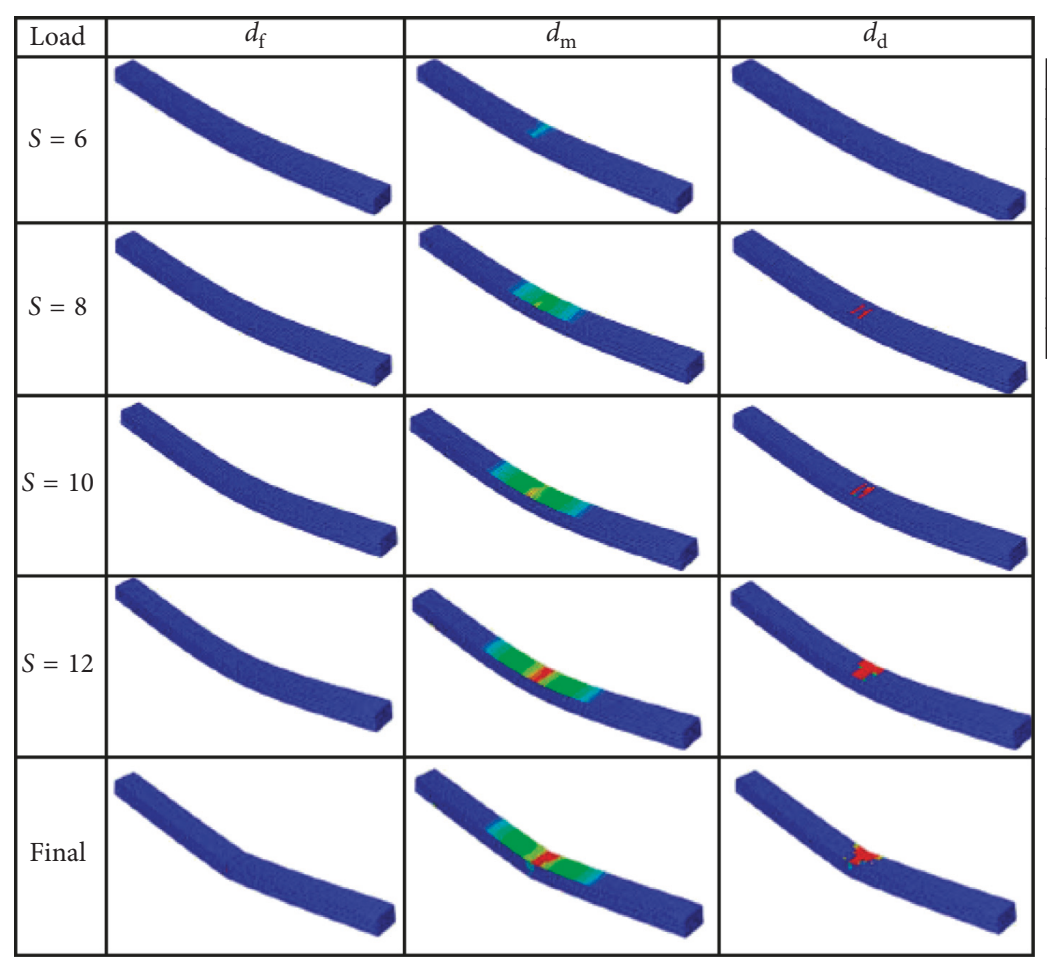

$+1.000 e+00$

$+9.000 e-01$

$+8.000 e-01$

$+7.000 e-01$

$+6.000 e-01$

$+5.000 e-01$

$+4.000 e-01$

$+3.000 e-01$

$+2.000 e-01$

$+1.000 e-01$

$+0.000 e+00$

(a)

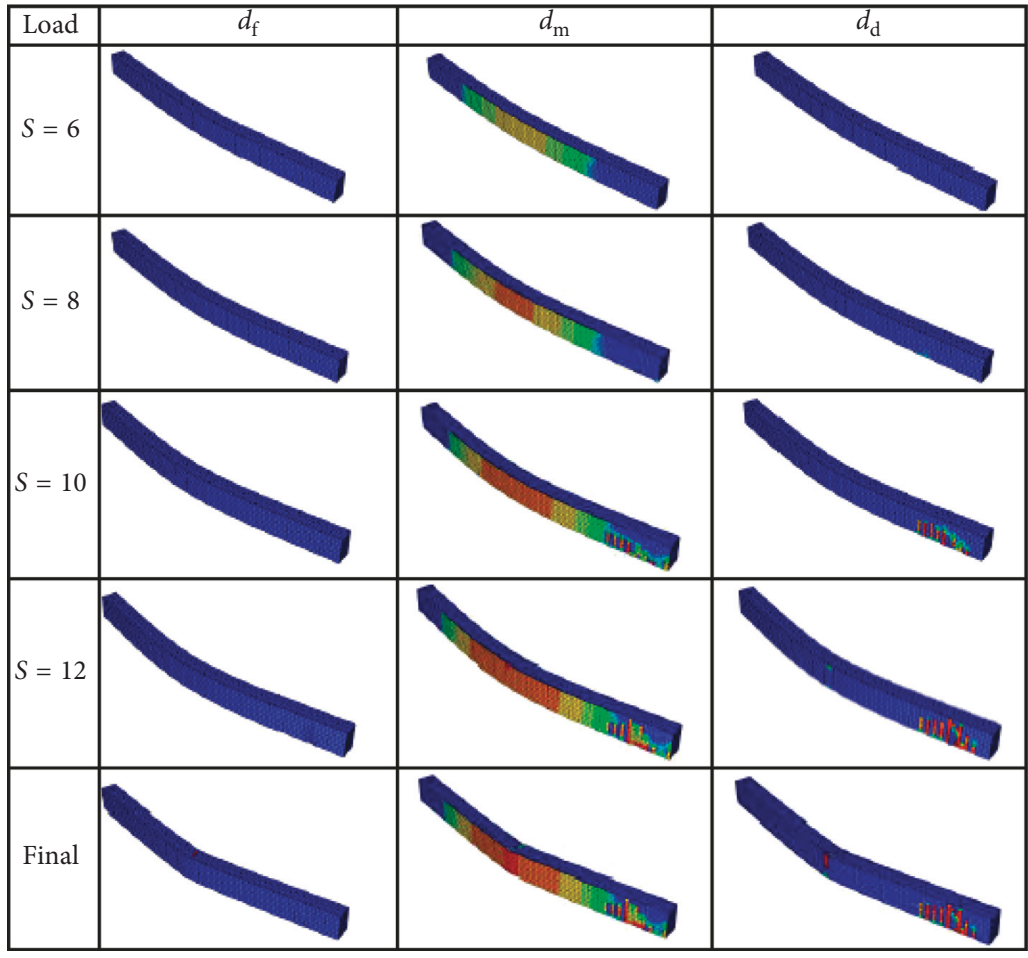

$+1.000 e+00$

$+9.000 e-01$

$+8.000 e-01$

$+7.000 e-01$

$+6.000 e-01$

$+5.000 e-01$

$+4.000 e-01$

$+3.000 e-01$

$+2.000 e-01$

$+1.000 e-01$

$+0.000 e+00$

(b)

Figure 9: Failure modes of longitudinal specimens. (a) Top surface. (b) Bottom surface.

which forbids the penetration of different parts. The frictional coefficient was taken as 0.3 for the tangential behavior of the contact interaction.

A comparison between numerical and experimental load-displacement curves is shown in Figure 8. A good agreement could be observed except that the stiffness of the numerical model is slightly higher than the experimental one, which can be related to the boundary conditions. The support pins were numerically simulated by constraining the out-of-plane displacements of the corresponding nodes. 


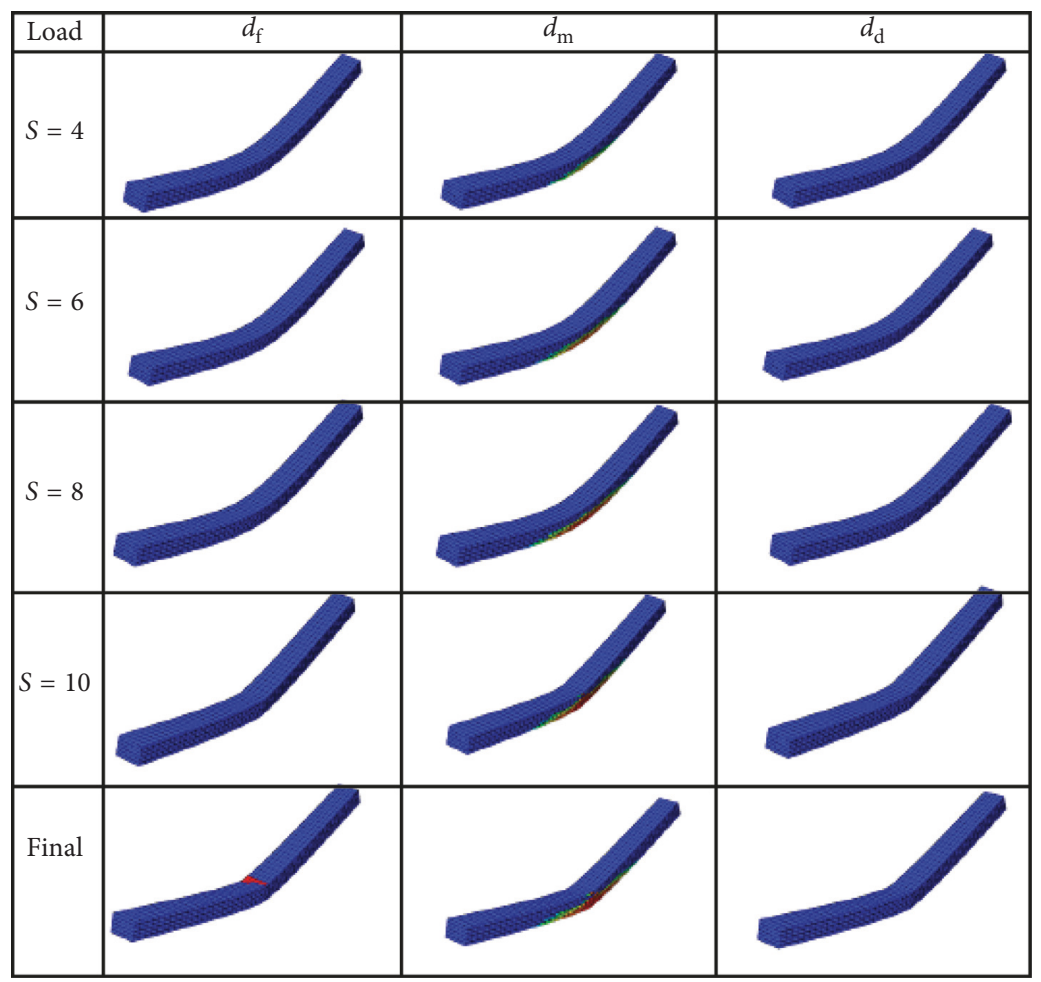

$+1.000 e+00$

$+9.000 e-01$

$+8.000 e-01$

$+7.000 e-01$

$+6.000 e-01$

$+5.000 e-01$

$+4.000 e-01$

$+3.000 e-01$

$+2.000 e-01$

$+1.000 e-01$

$+0.000 e+00$

(a)

\begin{tabular}{|l|l|l|l|}
\hline Load & $d_{\mathrm{f}}$ & $d_{\mathrm{m}}$ & $d_{\mathrm{d}}$ \\
\hline$S=4$ & & & \\
\hline$S=6$ & & & \\
\hline$S=8$ & & & \\
\hline Final & & & \\
\hline
\end{tabular}

$+1.000 e+00$

$+9.000 e-01$

$+8.000 e-01$

$+7.000 e-01$

$+6.000 e-01$

$+5.000 e-01$

$+4.000 e-01$

$+3.000 e-01$

$+2.000 e-01$

$+1.000 e-01$

$+0.000 e+00$

(b)

FIgURE 10: Failure modes of transverse specimens. (a) Top surface. (b) Bottom surface.

However, the bending of the specimen results in a reduction of the spacing span, and the nodes corresponding to the support pins were allowed to move in the in-plane directions.
Figures 9 and 10 present the different failure modes and damage propagation of the flexural specimens. In the analysis, the material is fully damaged when the damage variable, $d$, increased to its maximum. As shown in Figure 9, 
the matrix damage in the transverse direction, $d_{\mathrm{m}}$, occurred first when the displacement increased to $6.0 \mathrm{~mm}(S=6)$ on both the top and bottom surfaces. The matrix damage in transverse direction, $d_{\mathrm{m}}$, propagated, and the matrix damage through the thickness direction, $d_{\mathrm{d}}$, occurred on the top surface around the midspan when the displacement increased to $8.0 \mathrm{~mm}(S=8)$. The matrix damage, $d_{\mathrm{m}}$ and $d_{\mathrm{d}}$, continued to propagate once the displacement increased from $8.0 \mathrm{~mm}$ to $10.0 \mathrm{~mm}$. The ultimate failure occurred when the fiber damage, $d_{\mathrm{f}}$, at the top surface around the midspan increased to its maximum. This indicates that the fiber damage controls the longitudinal flexural strength. As shown in Figure 10, the matrix damage in transverse occurred when the displacement increased to $4 \mathrm{~mm}(S=4)$ on the bottom surface, while the matrix damage in the transverse direction, $d_{\mathrm{m}}$, continued to propagate when the displacement increased from $6.0 \mathrm{~mm}$ to $10.0 \mathrm{~mm}$. Furthermore, the fiber damage, $d_{\mathrm{f}}$, occurred when the displacement increased to $(S=10)$. No matrix damage in thickness direction, $d_{\mathrm{d}}$, occurred until the ultimate failure. The flexural load reached its maximum when the displacement is around $8.0 \mathrm{~mm}$, indicating the transverse flexural strength is controlled by the matrix damage in transverse direction $d_{\mathrm{m}}$.

\section{Conclusions}

Three-point flexural tests and finite element analysis were performed on pultruded laminate specimens for studying the flexural stiffness and strength. The following conclusions can be drawn from the study:

(1) The longitudinal and transverse flexural strengths of the pultruded composite laminate are $759.49 \mathrm{MPa}$ and $175.96 \mathrm{MPa}$, respectively. The longitudinal and transverse flexural moduli are 33.36 and $14.35 \mathrm{GPa}$, respectively. The failure mode of the longitudinal flexural specimen was the local crush on the top surface accompanied with local cracks on the bottom surface at the midspan of the specimens. For the transverse specimen in this study, failure was due to the development and propagation of local cracks at the bottom surface in the midspan.

(2) The theoretical load-displacement relationship of longitudinal and transverse flexural specimen agreed well with corresponding experimental relationship prior to the final failure or prior to the first-ply failure. The maximum normal stress of the longitudinal specimen occurred in the $0^{\circ}$-lamina close to the top and bottom surfaces as the load increased to its maximum, while the maximum normal stress of transverse specimen occurred in the $90^{\circ}$-lamina close to the top and bottom surfaces once the first-ply failure occurred. The maximum shear stress of both longitudinal and transverse specimens in the $0^{\circ}$ lamina occurred close to the top and the bottom surface of the pultruded laminate.

(3) Based on the continuum damage model proposed by the authors, this paper investigates the flexural behavior and failure pattern of the pultruded lamination. The theoretical and finite element results agreed well with the test results.

\section{Data Availability}

All the data used to support the findings of this study are included in the article.

\section{Conflicts of Interest}

The authors declare that they have no conflicts of interest.

\section{Acknowledgments}

The authors gratefully acknowledge the financial support provided by the National Natural Science Foundation (Grant nos. 51578406 and 51808398) of the People's Republic of China.

\section{References}

[1] A. S. Mosallam, A. Bayraktar, M. Elmikawi, S. Pul, and S. Adanur, "Polymer composites in construction: an overview," SOJ Materials Science \& Engineering (Open Access), vol. 2, no. 1, pp. 1-25, 2015.

[2] A. S. Mosallam, "Chapter 45: composites in construction," in Materials Selection Handbook, M. Kutz, Ed., pp. 1369-1422, John Wiley Publishing Co., New York, NY, USA, 2002.

[3] H. Xin, A. Mosallam, Y. Liu, C. Wang, and Y. Zhang, "Impact of hygrothermal aging on rotational behavior of web-flange junctions of structural pultruded composite members for bridge applications," Composites Part B: Engineering, vol. 110, pp. 279-297, 2017.

[4] H. Xin, Y. Liu, A. Mosallam, Y. Zhang, and C. Wang, "Hygrothermal aging effects on flexural behavior of pultruded glass fiber reinforced polymer laminates in bridge applications," Construction and Building Materials, vol. 127, pp. 237-247, 2016.

[5] H. Xin, A. Mosallam, Y. Liu, F. Yang, and Y. Zhang, "Hygrothermal aging effects on shear behavior of pultruded FRP composite web-flange junctions in bridge application," Composites Part B: Engineering, vol. 110, pp. 213-228, 2017.

[6] H. Xin, Y. Liu, A. Mosallam, and Y. Zhang, "Moisture diffusion and hygrothermal aging of pultruded glass fiber reinforced polymer laminates in bridge application," Composites Part B: Engineering, vol. 100, pp. 197-207, 2016.

[7] H. Xin, A. Mosallam, Y. Liu, and C. Wang, "Hygrothermal aging effects on axial behaviour of pultruded web-flange junctions and adhesively bonded build-up bridge members," Journal of Reinforced Plastics and Composites, vol. 37, no. 1, pp. 13-34, 2018.

[8] American Association of State Highway Transportation Officials (AASHTO), AASHTO LRFD Bridge Design Specifications, American Association of State Highway Transportation Officials, Washington, DC, USA, 3rd edition, 2004.

[9] A. S. Mosallam, L. Feo, A. Elsadek, S. Pul, and R. Penna, "Structural evaluation of axial and rotational flexibility and strength of web-flange junctions of open-web pultruded composites," Composites Part B: Engineering, vol. 66, pp. 311-327, 2014.

[10] L. Feo, A. S. Mosallam, and R. Penna, "Mechanical behavior of web-flange junctions of thin-walled pultruded I-profiles: an 
experimental and numerical evaluation," Composites Part B: Engineering, vol. 48, pp. 18-39, 2013.

[11] T. J. Schniepp, Design Manual Development for a Hybrid, FRP Double-Web Beam and Characterization of Shear Stiffness in FRP Composite Beams, Virginia Polytechnic and State University, Blacksburg, VA, USA, 2002.

[12] H. Xin, Y. Liu, J. He, H. Fan, and Y. Zhang, "Fatigue behavior of hybrid GFRP-concrete bridge decks under sagging moment," Steel and Composite Structures, vol. 18, no. 4, pp. 925-946, 2015.

[13] H. Xin, Y. Liu, and A. Du, "Thermal analysis on composite girder with hybrid GFRP-concrete deck," Steel and Composite Structures, vol. 19, no. 5, pp. 1221-1236, 2015.

[14] H. Xin, A. Mosallam, Y. Liu, C. Wang, and Y. Zhang, "Analytical and experimental evaluation of flexural behavior of FRP pultruded composite profiles for bridge deck structural design," Construction and Building Materials, vol. 150, pp. 123-149, 2017.

[15] H. Xin, A. Mosallam, Y. Liu et al., "Experimental and numerical investigation on in-plane compression and shear performance of a pultruded GFRP composite bridge deck," Composite Structures, vol. 180, pp. 914-932, 2017.

[16] H. Xin, A. S. Mosallam, Y. Liu, C. Wang, and J. He, "Experimental and numerical investigation on assessing local bearing behavior of a pultruded GFRP bridge deck," Composite Structures, vol. 204, pp. 712-730, 2018.

[17] A. Riccio, P. Linde, A. Raimondo, A. Buompane, and A. Sellitto, "On the use of selective stitching in stiffened composite panels to prevent skin-stringer debonding," Composites Part B: Engineering, vol. 124, pp. 64-75, 2017.

[18] W. Van Paepegem, I. De Baere, and J. Degrieck, "Modelling the nonlinear shear stress-strain response of glass fibrereinforced composites. Part II: model development and finite element simulations," Composites Science and Technology, vol. 66, no. 10, pp. 1465-1478, 2006.

[19] H. Xin, Y. Liu, A. S. Mosallam, J. He, and A. Du, "Evaluation on material behaviors of pultruded glass fiber reinforced polymer (GFRP) laminates," Composite Structures, vol. 182, pp. 283-300, 2017.

[20] P. Soden, M. J. Hinton, and A. S. Kaddour, "Lamina properties, lay-up configurations and loading conditions for a range of fibre-reinforced composite laminates," Composites Science and Technology, vol. 58, no. 7, pp. 1011-1022, 1998.

[21] Standardization Administration of the People's Republic of China (SAPRC), Fiber Reinforced Plastic Composites-Determination of Flexural Properties, GB/T1449-2005, SAPRC, Beijing, China, 2005, In Chinese.

[22] Z. M. Huang and Y. X. Zhou, Strength of Fibrous Composites, Springer Press, New York, NY, USA, 2011.

[23] E. J. Barbero, Introduction to Composite Materials Design, CRC Press, Boca Raton, FL, USA, 2010.

[24] V. Abaqus, 6.14 Documentation, Dassault Systems Simulia Corporation, Vélizy-Villacoublay, France, 2014. 


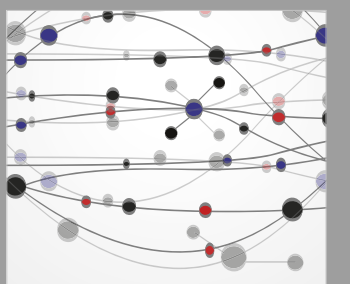

The Scientific World Journal
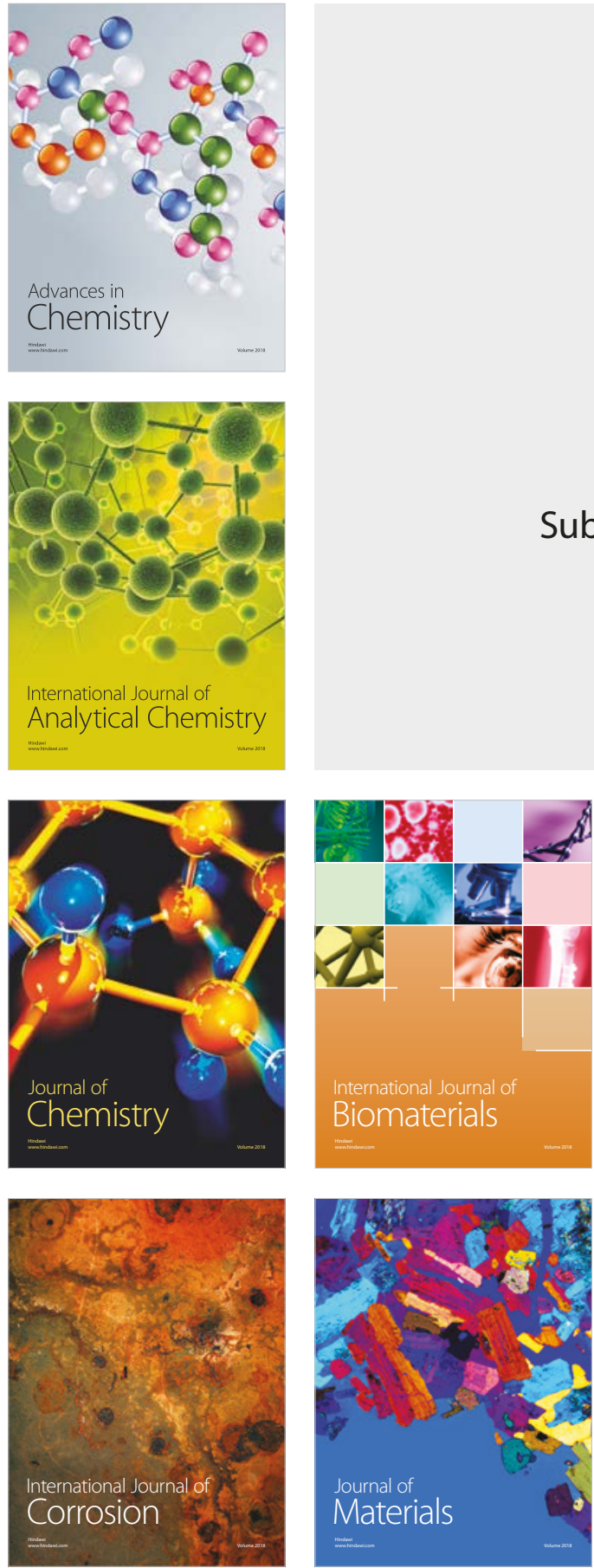

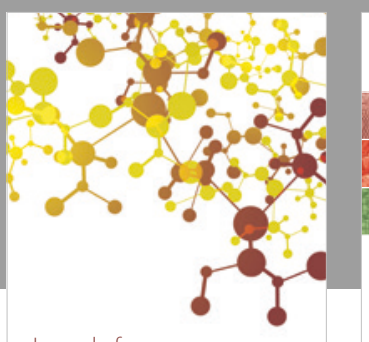

Journal of

Applied Chemistry
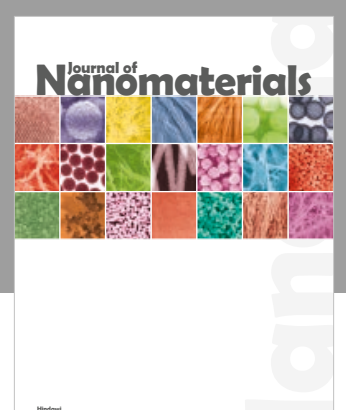

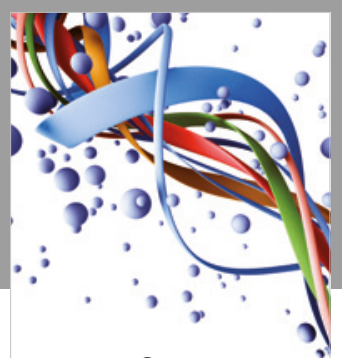

Scientifica

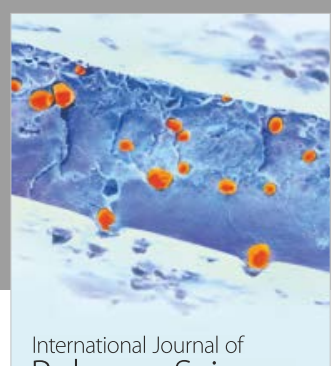

Polymer Science

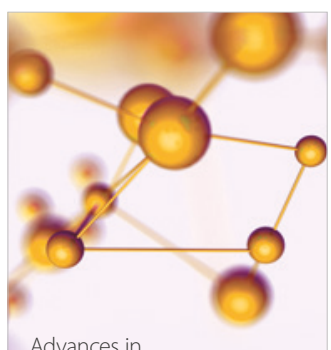

Physical Chemistry
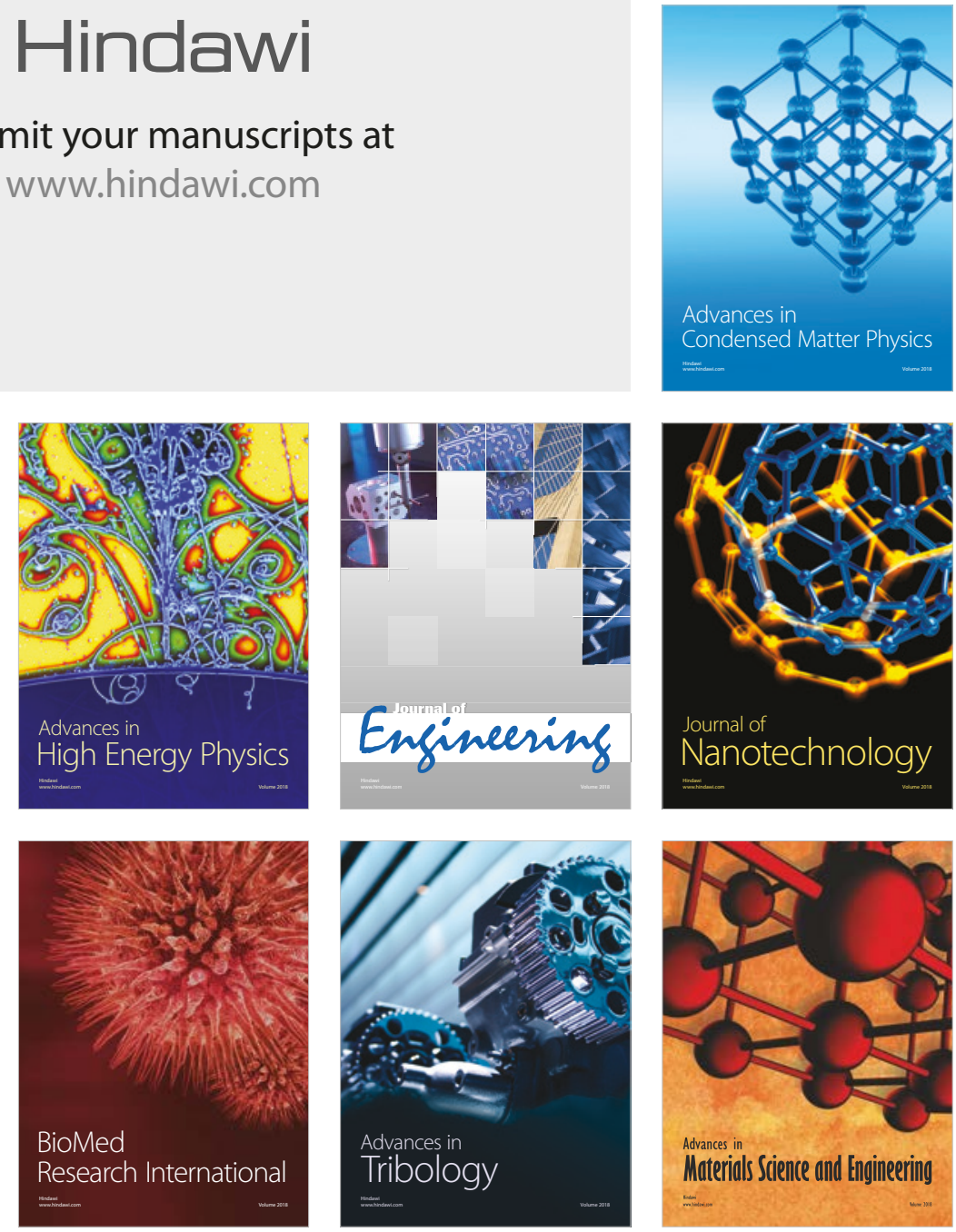